\title{
A TRADUÇÃO PELO PRISMA DA LOCALIZACÃO NA ECONOMIA INFORMACIONAL
}

\author{
Érika Nogueira de Andrade Stupiello*
}

RESUMO: Este trabalho examina o espaço que a tradução ocupa na indústria da localização. Vista como uma atividade que lida basicamente com a recuperação de significados por meio de sistemas de memórias, a tradução é concebida como um trabalho que compõe uma pequena parte do processo de localização, que envolve a adaptação de produtos de alta tecnologia às necessidades específicas dos mercados estrangeiros em que serão introduzidos. A análise proposta apresenta algumas das estratégias de autoria controlada aplicada ao material de origem a ser localizado; discute, ademais, a escamoteação da igualdade de acesso à tecnologia, especialmente por meio da inferiorização do trabalho de tradução.

UNITERMOS: localização; tradução; memórias de tradução; autoria controlada.

ABSTRACT: This paper examines the space translation fills in the localization industry. Perceived as an activity basically dealing with the recovery of meanings stored in translation memory systems, translation is conceived as making up just a small part of the localization process, which comprises tailoring high-technology products to the specific needs of the foreign markets where they shall be introduced. The proposed analysis presents some of the controlled authoring strategies applied to the original

* Doutoranda do Programa de Estudos Linguísticos da Universidade Estadual Paulista (campus de São José do Rio Preto). 
material to be localized and discusses the concealment of equal access to technology, mainly by downgrading the translation work.

KEYWORDS: localization; translation; translation memories; controlled authoring.

\section{Introdução}

Um dos efeitos dos avanços nas tecnologias de informação e comunicação na contemporaneidade é o progressivo aumento na demanda por materiais textuais que possam ser instantaneamente direcionados a membros das mais diversas comunidades linguísticas e culturais. Essa situação é possibilitada pelas facilidades de acesso a um mercado considerado global por estar conectado à internet, local em que produtos e serviços são virtualmente apresentados aos mais diversos públicos e oferecidos à comercialização que, para se concretizar, requer a disponibilização simultânea das informações sobre os produtos em todas as línguas dos mercados alvo.

A atividade de localização originou-se em função da necessidade de empresas internacionais criarem formas de conquistar novos públicos-consumidores de produtos cuja oferta era anteriormente limitada, devido à inexistência de meios de contato com mercados mais longínquos. Segundo Esselink (2006), o deslocamento do uso de programas de hardware e software do universo acadêmico e empresarial para o ambiente do usuário comum na década de oitenta gerou a necessidade de criar e adaptar os recursos desses programas às exigências e às necessidades de um público cujas preferências eram, naquela época, desconhecidas. Os então novos usuários de computadores pessoais criaram uma demanda por software e outros aplicativos que não somente os capacitassem a trabalhar de modo mais eficaz, mas que refletissem "os padrões e hábitos locais, inclusive a lingua local” (Esselink, 2006:22) ${ }^{1}$. Visando a esse fim, os

1 Esta e as demais traduções de citações em lingua estrangeira foram feitas por mim.

TradTerm, 15, 2009, p. 101-112 
processadores de texto produzidos passariam por modificações internas em sua interface para admitirem o uso de conjuntos de caracteres e recursos linguísticos específicos em outras línguas, tais como a hifenização e a ortografia.

Essas modificações foram vistas, a princípio, como um grande desafio para a indústria de desenvolvimento de programas informatizados, como explica Debbie Folaron (2006), professora e pesquisadora em tradução e localização na Universidade Concórdia, em Montreal, Canadá. Para os programadores e engenheiros de software, atuando majoritariamente na costa oeste dos Estados Unidos no desenvolvimento de programas em língua inglesa, a integração da tarefa de adaptação desses produtos a mercados internacionais significava adicionar um estágio de trabalho "linguística e culturalmente estrangeirizador" muito diferente da rotina de programação, escrita e produção técnica para o mercado doméstico, com a qual estavam acostumados (Folaron, 2006:197). Se, por um lado, o trabalho linguístico e cultural foi recebido como uma "adição não bem vinda determinada pelo setor de marketing e gerenciamento", por outro, as novas exigências foram muito bem recebidas por tradutores e agências de tradução que, desde então, começaram a adquirir recursos, em forma de ferramentas eletrônicas e outras tecnologias, que lhes munissem para dar conta das novas exigências de um ascendente mercado de traduções (idem, ibidem).

A expansão do mercado consumidor internacional de software e outros produtos de alta tecnologia exigiu a divisão dos trabalhos de projeto desses produtos e seu condicionamento a diferentes consumidores, delegando o trabalho de localização a empresas que passaram a se dedicar à prestação desse serviço. Na atualidade, o termo localização é associado à atividade que envolve a adaptação linguística e cultural e a tradução de materiais em formato eletrônico - softwares, páginas da internet, jogos, aplicativos eletrônicos e outros tipos de produtos de alta tecnologia - para os mercados locais específicos, onde serão introduzidos e comercializados.

Sendo um ramo que tem se desenvolvido paralelamente à implementação das novas tecnologias de informação e comunicação, a chamada "indústria de localização" opera com materiais em formato digital e em contínua mutação, um fato que a obriga a

TradTerm, 15, 2009, p. 101-112 
atualizar constante e rapidamente suas atividades. Os trabalhos envolvidos no processo de localização são, em geral, resumidos pela sigla em inglês GILT, em referência às atividades de Globalização, Internacionalização, Localização e Tradução².

Especificamente na indústria de localização, o processo de globalização abrange um conjunto de estratégias para o desenvolvimento, a tradução, a comercialização e a distribuição de um produto em escala mundial. Globalizar um produto, então, envolve a procura por oportunidades de inseri-lo em mercados estrangeiros. Isso implica o planejamento de ações e de adaptações na concepção de sua primeira versão, realizada durante uma etapa conhecida como internacionalização, para possibilitar sua adequação aos mercados em que será introduzida pelo trabalho de localização.

Dependendo do ângulo pelo qual é abordada, a localização pode conduzir a diferentes relações com a tradução; todas, de alguma forma, refletindo as assimetrias na descrição das duas práticas. Para Cronin (2003), diferentemente da tradução, que tem uma "longa história de dificuldade e aproximação", o uso do termo localização "implica um processo totalmente novo, que se compromete sem esforço com o local"', constituindo uma forma de "mais uma vez, tornar invisível e despolitizar a tradução no mundo moderno" (Cronin, 2003:63).

De acordo com teóricos da tradução, como Biau Gil e Pym (2006), a localização seria apenas "um nome extravagante para o ato de adaptar um texto para um público leitor alvo específico, algo que os tradutores fazem há milênios" (Biau Gil e Pym, 2006:14). Segundo Tymoczko (2007), o termo localização teria sido criado para se referir a traduções "naturalizadas ao extremo para a cultura de chegada" e bastante diversas dos textos que lhe deram origem desestabilizando [desse modo] distinções tradicionais entre "original' e 'tradução"' (Tymoczko, 2007:66). Já para os fabricantes de softwares que contratam serviços de localização, por exemplo, a

2 Sigla criada pela Associação de Padrões da Indústria de Localização (Localization Industry Standards Association - LISA), que tem como membros as empresas atuantes na área de localização, e cujo endereço eletrônico é www.lisa.org.

TradTerm, 15, 2009, p. 101-112 
tradução constituiria somente parte do trabalho (maior e mais complexo) de adequação de um produto ao local que será comercializado.

Este artigo, assim, enfoca o trabalho de localização como parte do processo de internacionalização, buscando evidenciar como algumas das estratégias empregadas para localizar um produto, que teriam por intenção adequá-lo a um determinado local, manipulam e delimitam as informações que serão disponibilizadas aos usuários de produtos localizados.

\section{0 controle da produção de origem e da tradução durante as etapas de internacionalização e localização}

O trabalho de internacionalização de um produto realiza-se na medida em que se desenvolvem seu projeto e a composição da documentação que o acompanhará. Busca-se, desde o início, a generalização na elaboração das informações que descrevem determinado produto, de forma que ele seja capaz de ser oferecido em diferentes línguas e para convenções culturais diversas sem a necessidade de alterações significativas em sua concepção. Nessa etapa, dois aspectos fundamentais de produção para viabilizar a localização são: i) a inclusão de recursos compativeis com caracteres específicos de uma língua (como aqueles usados pelo japonês, ou o chinês); e ii) a separação do material textual do código fonte do software.

Durante a fase de tradução, somente o texto a ser traduzido e editado é exibido ao tradutor de forma a evitar que os códigos de funcionamento do programa sejam alterados. As estratégias de internacionalização são frequentemente denominadas de "redação para tradução" ou "redação para um público global", e são aplicadas também nos arquivos de ajuda, que acompanham os programas de software e aparecem, cada vez mais, em páginas da internet de empresas internacionais (Esselink, 2000:3).

Ainda na fase de internacionalização, atenção especial é dedicada para que materiais textuais de programas em desenvolvimento sejam preparados, de forma a garantir sua funcionalidade $\mathrm{e}$ aceitação nos mercados para os quais serão direcionados, bem como assegurar que os mesmos sejam passiveis de serem localizados numa etapa seguinte. Conforme relaciona Esselink (2000), a inter-

TradTerm, 15, 2009, p. 101-112 
nacionalização define o sucesso da localização e da apresentação de um produto; por isso, a documentação correspondente aos programas em desenvolvimento requer uma redação "concisa, clara, que não contenha jargões ou gírias e que seus conteúdos estejam livres de exemplos ou referências culturalmente específicos" (Esselink, 2000:25). Estratégias de controle de uso da língua e do estilo de elaboração textual são rotineiramente aplicadas e visam a garantir a uniformização da tradução da documentação dos programas por meio das seguintes promessas:

- A informação apresentada pode ser interpretada somente de uma forma, reduzindo a ambiguidade e melhorando a legibilidade.

- O uso coerente do estilo e da terminologia é imposto.

- A traduzibilidade do texto é aprimorada, especialmente quando ferramentas de auxílio à tradução como, por exemplo, a tradução automática, são usadas no processo de localização.

- O prazo para comercialização dos produtos localizados é reduzido devido ao aumento da velocidade da tradução, em geral, de 25\%. (Esselink, 2000:30) ${ }^{3}$

Manuais de estilo e programas específicos para controlar a terminologia e a composição dos textos de origem são bastante utilizados nessa fase com o objetivo de reduzir custos e prazo durante a etapa de tradução. Além de garantir o cumprimento do tempo de entrega do produto final, o uso simplificado da língua tornaria possivel também seu processamento semi-automático, por meio de sistemas de memórias de tradução, ferramentas de

3 " - The information presented can only be interpreted in one way, so ambiguity is reduced and readability improved.

- Consistent use of style and terminology is enforced.

- The translatability of the text is improved, especially when computerassisted translation tools, e.g. machine translation, are used in the localization process.

- The time to market for localized products can be shortened because translation speed will be increased, often up to $25 \%$.".

TradTerm, 15, 2009, p. 101-112 
grande utilização em trabalhos de localização, auxiliando, em especial, a padronização de projetos de tradução desenvolvidos por equipes de tradutores.

Em dissertação de mestrado intitulada Memórias de tradução: auxilio ou empecilho?, Rieche (2004) lembra que, na indústria de localização, anteriormente ao advento dos sistemas de memórias de tradução, "a cada nova versão ou atualização de um produto, por exemplo, era necessário traduzir desde o início todo o material" (Rieche, 2004:13). Segundo a tradutora, o grande atrativo dos anúncios de vendas de sistemas de memória de tradução, em que aparecem ganhos de produtividade e promessas de aumento de competitividade em preço, proporcionado pelo possivel reaproveitamento de traduções anteriores, faria das memórias ferramentas cada vez mais utilizadas por tradutores cujo desejo fosse o de se manter preparados para as exigências desse mercado.

Em grandes projetos desenvolvidos nessa indústria, nos quais um considerável número de tradutores é envolvido, a vantagem das memórias estaria no compartilhamento simultâneo de glossários por tradutores, beneficiando, sobretudo, aqueles menos experientes, além do compartilhamento dos resultados de pesquisas terminológicas, cujos resultados são armazenados no banco de dados, geralmente fornecido no início do trabalho.

Helbich (2006), diretor de uma empresa de produção e tradução de documentação multilíngue, também defende a adoção de uma escrita controlada para composição de materiais textuais a serem localizados. Conforme enumera, a prática de "escrita para reutilização" contaria com três elementos principais que garantiriam seu reaproveitamento em atualizações futuras de documentação, assim como a redução nos custos e prazos de tradução: um conjunto de "regras práticas de autoria", uma ferramenta de memória para consulta e recuperação do corpus de origem nela armazenada e um sistema de memória de tradução, utilizado, de preferência, em sintonia com a memória de autoria, a fim de propiciar o máximo de reaproveitamento de traduções já realizadas (Helbich, 2006:4). A eliminação de informações consideradas "irrelevantes" no texto de origem seria uma das formas de proporcionar ganhos em tempo e prazo no trabalho de localização, como no exemplo seguinte: 
Texto de origem em inglês sem autoria controlada

If you add any label to a $C D$, insert more than one $C D$ into the slot at a time, or attempt to play scratched or damaged $C D s$, you could damage the $C D$ player. When using the $C D$ player, use only $C D$ s in good condition without any label, load one $C D$ at a time, and keep the $C D$ player and the loading slot free of foreign materials, liquids, and debris.
Texto de origem em inglês com autoria controlada

Do not apply paper labels to discs. The labels may get caught in the player. Keep the loading slot free of foreign materials, liquids and debris.

Do not use scratched or damaged discs.

O texto de origem não-controlado faz uso dos recursos de parataxe e hipotaxe em sua composição, ao passo que o texto regulado é composto somente por orações absolutas com orientações concisas. O emprego de um número menor de palavras e frases mais curtas seria um meio de garantir a redução dos custos da tradução, e isso de duas formas: primeiramente, pela diminuição do número de palavras a serem traduzidas (o que reduziria a remuneração do tradutor) e, em segundo lugar, pelo aumento das chances de reaproveitamento de segmentos anteriormente traduzidos e armazenados na memória que, em geral, não são remunerados quando recuperados desses bancos de dados. Um exemplo estaria na estratégica de substituição do termo "CD" por "disco", o que permitiria a reutilização parcial, ou mesmo total, desse material textual como referência a DVDs.

A estratégia de padronização linguística do material textual acompanhando os produtos a serem localizados faria do inglês, língua em que é majoritariamente redigida a documentação dos recursos e programas tecnológicos atuais, uma espécie de "língua franca", facilitando a distribuição da documentação nela redigida. Para Pym (2004), os trabalhos envolvidos no estágio de internacionalização assumem uma função ideológica, que implica a noção de que "um único texto 'internacional' será adequado para todos os locales, de alguma forma colocando nossa tecnologia nos tempos anteriores à Torre de Babel" (Pym, 2004:36). Nesse cenário, as tentativas de padronização linguística fariam do inglês, língua de origem da maior parte dos materiais textuais produzidos para localização, uma espécie de língua auxiliar da comunicação que, submetida a determinados moldes de expressão, possibilitaria também a automação de sua tradução para outras línguas, acelerando a dis-

TradTerm, 15, 2009, p. 101-112 
tribuição da documentação assim elaborada. Pym equipara as táticas de padronização linguística da língua inglesa, empregadas durante a internacionalização, a um trabalho de "tradução controlada", implantado há algum tempo na tradução de documentações na União Européia, "onde o inglês está se aproximando de uma interlíngua e aqueles que trabalham com essa língua estão, consequentemente, se tornando escrivões ou revisores oficiais, em vez de tradutores" (Pym, 2004:36).

No presente, sendo a maioria dos produtos e serviços a serem localizados conceituados numa língua inglesa idealmente padronizada por determinadas regras de redação dos textos de origem, o trabalho de tradução é entendido e remunerado como uma operação de busca e, sempre que possivel, de recuperação de equivalentes entre uma língua inglesa "neutra" e as outras linguas. Essa aparente imparcialidade da lingua de origem, uma forma de controle de produção e de assegurar também a neutralidade das traduções resultantes, é analisada a seguir.

\section{3 olhar da crítica sobre a delimitação do espaço da tradução na localização}

O desejo de uma comunicação em diferentes línguas instantaneamente inteligivel, numa era em que a diversidade linguística pode constituir uma barreira, é denominada por Cronin (2003) de "novo-babelianismo". A superação desse obstáculo estaria, para muitos, na adoção de uma única língua que, de sua "posição dominante", seria traduzida para aquelas consideradas inferiores, cabendo aos falantes destas encarregarem-se dos custos da tradução. Na visão de Cronin, os esforços para que a língua inglesa permaneça como a língua da comunicação global teriam particularmente em vista o deslocamento do "ônus da tradução" para aqueles que não falam a língua dominante e que "não só devem traduzirem a si mesmos para o inglês, como traduzirem do inglês para sua própria língua" (Cronin, 2003:60).

A ênfase na criação e manutenção de um contexto prébabélico de comunicação acabaria por eliminar as vozes de línguas que ocupam posição inferior (e que manteriam um status de língua traduzida) em relação à língua considerada de origem. Assim, os

TradTerm, 15, 2009, p. 101-112 
110

textos primeiramente elaborados numa língua - na maioria das vezes, o inglês - e, então, traduzidos segundo os critérios impostos pela indústria de localização, manteriam na tradução a mesma função do texto de origem, porém encobrindo normas e valores anglófonos. Além disso, a implementação de meios para uniformizar a lingua, supostamente produzindo textos de origem transparentes e totalmente traduziveis, conduziria a uma dispersão da autoria desses materiais a serem traduzidos, dissipando também a responsabilidade autoral por textos assim produzidos.

Sendo o "inglês padronizado" a língua de origem da maioria dos produtos atualmente localizados, o trabalho de tradução é concebido pela literatura em localização - especialmente em trabalhos de teor técnico, como A Practical Guide to Localization, de Bert Esselink (2000) - como uma operação de busca e, sempre que possível, de recuperação de equivalentes entre o inglês e as outras línguas. Todo o trabalho envolvido na tradução de um texto, que necessariamente abrange a pesquisa terminológica, a reconstrução de um texto numa outra língua, a edição e revisão de texto e a reelaboração do leiaute da página, é minimizado, pois adaptações e ajustes na organização interna de um produto, nos termos de garantia e, até nos formatos de hora, data, e alterações de símbolos, ícones e cores de visualização são consideradas como parte de um processo maior, designado localização.

A tendência em abordar a localização e a tradução como operações estanques não é sem motivos. Tradicionalmente, a tradução é vista como um processo dificultoso, e quase sempre incompleto e imperfeito de aproximação entre duas línguas e culturas, conforme discute, por exemplo, Tymoczko (2007). A ideia preceituada na literatura sobre localização seria a de que se trata de um processo que, partindo de uma língua de origem pré-condicionada e pretensiosamente neutra, teria sempre sucesso na "conquista" do significado local, como exemplificam as análises de Cronin (2003) e Pym (2004). Para obter êxito em trabalhos de localização, a tradução deve procurar reaproveitar o maior número possivvel de opções anteriores, uniformizando as escolhas de forma a evitar, por exemplo, o redimensionamento das caixas de diálogos dos programas, quando localizados para outras línguas. Ao consignar o trabalho de adaptação cultural à etapa de localização, a tradução passa a

TradTerm, 15, 2009, p. 101-112 
ser, como caracteriza Pym, "reduzida a algo muito pequeno, talvez o aspecto menos interessante da localização" (Pym, 2004:51).

A idealização de apagamento das especificidades da cultura de origem de um produto, a fim de aclimatá-la às culturas que a receberão, acaba assegurando a detenção da tecnologia àqueles que se posicionam no pólo de produção e distribuição da tecnologia. Conforme argumenta Pym, "o cultivo da diferença pela localização é também a manutenção da assimetria" (Pym, 2004:47). Se tomarmos, por exemplo, a versão localizada para o português brasileiro do Microsoft Windows XP, vemos que os comandos principais, os menus e as caixas de diálogos apresentam suas versões localizadas já padronizadas e que assim são conservados quando o sistema é atualizado. Por outro lado, se necessitarmos de informações mais detalhadas sobre o funcionamento do programa, como os códigos fontes ou a linguagem técnica em que o programa foi desenvolvido, temos, na maioria das vezes, de recorrer ao original em inglês. $\mathrm{O}$ usuário de programas localizados como esse é, por meio da localização, concebido como um "consumidor passivo" a quem é concedido acesso limitado à língua da tecnologia.

\section{Considerações finais}

A atividade de localização pauta-se na inclusão das diferenças entre línguas e culturas, principalmente ao tornar possivel o acesso a um produto por públicos diversos. Por outro lado, dentre as várias etapas de cunho basicamente comercial que são listadas como componentes do processo de localização, é especificamente pela tradução que um determinado público aproxima-se de um produto a ele oferecido. Ainda que seu papel seja subestimado na indústria de localização, a tradução desempenha um papel indelével na recriação de um texto estrangeiro e nas novas relações desse texto com a nova realidade cultural e linguística da qual fará parte.

Pensar a tradução somente como uma operação à parte do

processo de localização dissimula as adaptações, inclusões, exclusões e outras adequações pelas quais um texto inevitavelmente passa ao ser traduzido, além de perpetuar a posição passiva de consumidores de produtos localizados idealmente neutros.

TradTerm, 15, 2009, p. 101-112 


\section{Agradecimento}

Agradeço à FAPESP pelos recursos da bolsa de doutorado (processo no. 06/60974-5) que possibilitaram a pesquisa para elaboração deste artigo.

\section{Referências bibliográficas}

BIAU GIL, José Ramón; PYM, Anthony (2006) Technology and Translation (a pedagogical overview). In: PYM, A., A., PEREKRESTENKO, A., STARINK, B. Translation technology and its teaching. Tarragona, Espanha. Disponivel em <http://isg.urv.es/ publicity/isg/publications/technology_2006/index.htm>. Acesso em 14 de março de 2009.

CRONIN, Michael (2003) Translation and Globalization. Londres: Routledge.

ESSELINK, Bert (2000) A Practical Guide to Localization. Amsterdam/ Philadelphia: John Benjamins.

(2006) The Evolution of Localization. In: PYM, A., A., PEREKRESTENKO, A., STARINK, B. Translation technology and its teaching. Tarragona, Espanha. Disponivel em <http://isg.urv.es/ publicity/isg/publications/technology_2006/index.htm>. Acesso em 14 de março de 2009.

FOLARON, Debbie (2006) A Discipline Coming of Age in the Digital Age. In: DUNNE, Keiran J. (ed.). Perspectives on Localization. American Translators Association Scholarly Monograph Series XIII. Amsterdam/Philadelphia: John Benjamins, pp. 195-219.

HELBICH, Carl (2006) Controlled Authoring: writing for re-use. Multilingual: writing for translation, pp. 3-6.

PYM, Anthony (2004) The moving text: localization, translation and distribution. Amsterdam: John Benjamins.

RIECHE, Adriana C. (2004) Memórias de tradução: auxilio ou empecilho? Dissertação de Mestrado em Letras. Rio de Janeiro: PUC-Rio.

TYMOCZKO, Maria (2007) Enlarging translation, empowering translators. Manchester: St. Jerome.

TradTerm, 15, 2009, p. 101-112 